\title{
Revisiting food security in 2021: an overview of the past year
}

\author{
Serge Savary ${ }^{1} \cdot$ Stephen Waddington $^{2} \cdot$ Sonia Akter $^{3} \cdot$ Conny J. M. Almekinders ${ }^{4} \cdot$ Jody Harris $^{5} \cdot$ Lise Korsten $^{6}$. \\ Reimund P. Rötter ${ }^{7}$. Goedele Van den Broeck ${ }^{8}$
}

Published online: 10 February 2022

(c) International Society for Plant Pathology and Springer Nature B.V. 2022

\begin{abstract}
Articles published in Food Security in 2021 are reviewed, showing a wide range of topics covered. Many articles are directly linked with "food" and associated terms such as "nutritive", "nutrition", "dietary", and "health". Another important group is linked with (food) "production" and a range of connected terms including: "irrigation", "cultivated", "organic", "varieties", "crop", "vegetable", and "land". A third group of terms refers to the scales at which food security is considered: "household", "farmer", "farm", "smallholder", "community", "nation" and "region". A few themes of Food Security are considered: (1) food supply and demand, food prices, and global trade; (2) food security in households; (3) food production; (4) value chains and food systems; (5) the evolution of the concept of food security; and (6) global nutrition. In a last section, perspectives for Food Security are discussed along four lines of thoughts: the level of inter-disciplinary research published in Food Security; the importance of the Social Sciences for food security as a collective good underpinned by other collective goods within food systems; the balance between the Global South and the Global North in Food Security; and a warning that urgent global challenges that vitally interact with food security may be left unattended as a result of the current public health emergency.
\end{abstract}

Keywords Food security $\cdot$ Nutrition $\cdot$ Agriculture $\cdot$ Household $\cdot$ Communities $\cdot$ World food system

Serge Savary

eicfoodsec@gmail.com

1 Editor-in-Chief, Food Security, INRAE, Auzeville, France

2 Deputy Editor-in-Chief, Food Security, Cuernavaca, Mexico

3 Senior Editor, Lee Kuan Yew School of Public Policy, National University of Singapore, Food Security, Bukit Timah, Singapore

4 Senior Editor, Knowledge, Technology and Innovation, WUR , Food Security, Wageningen, The Netherlands

5 Senior Editor, Thailand and Institute of Development Studies, Food Security, World Vegetable Center, Chiang Mai, UK

6 Senior Editor, Food Security, Department of Science and Technology/National Research Foundation, Centre of Excellence Food Security at the University of Pretoria, Pretoria, South Africa

7 Senior Editor, Food Security, Chair, Tropical Plant Production and Agrosystems Modelling (TROPAGS), Department of Crop Sciences, Georg-August-University, Göttingen, Germany

8 Senior Editor, Food Security, Earth and Life Institute, UCLouvain, Louvain-la-Neuve, Belgium
The year 2021 was eventful. The wide range of topics covered by articles published in Food Security (Fig. 1) reflects a diversity of subjects, questions and concepts. Figure 1, which is derived from 99 analysed article abstracts, indicates a number of dominating key words, in various groups. One group concerns "food" (with associated terms such as, e.g.: nutritive, nutrition, dietary, and health) and another one concerns "production" (with a host of connected terms including: irrigation, cultivated, organic, varieties, crop, vegetable, and land). A third, less apparent but pervasive set of terms refers to scales, with terms such as: household, farmer, farm, smallholder, community, nation and region. There also is the binary "security" vs "insecurity". The image of Fig. 1 is only a canvas; it does indicate the weight in frequency of terms, but it fails to show how and to what extent words are connected. Figure 1 may also overlook elements that refer to various objects, such as the physical environment, including climate change, and the settings where humans live, including cities or the rural environment.

The present review is based on the analysis of Food Security articles that have been published in 2021. It provides some insight among these many connections and uncovers some key aspects of the Food Security landscape. 
Fig. 1 Patterns of words in Food Security articles in 2021 The figure is based on the word contents of 99 analysed (WordCloud.com: https://classic. wordclouds.com/) articles. Noninformative adverbs, adjectives and verbs have been removed

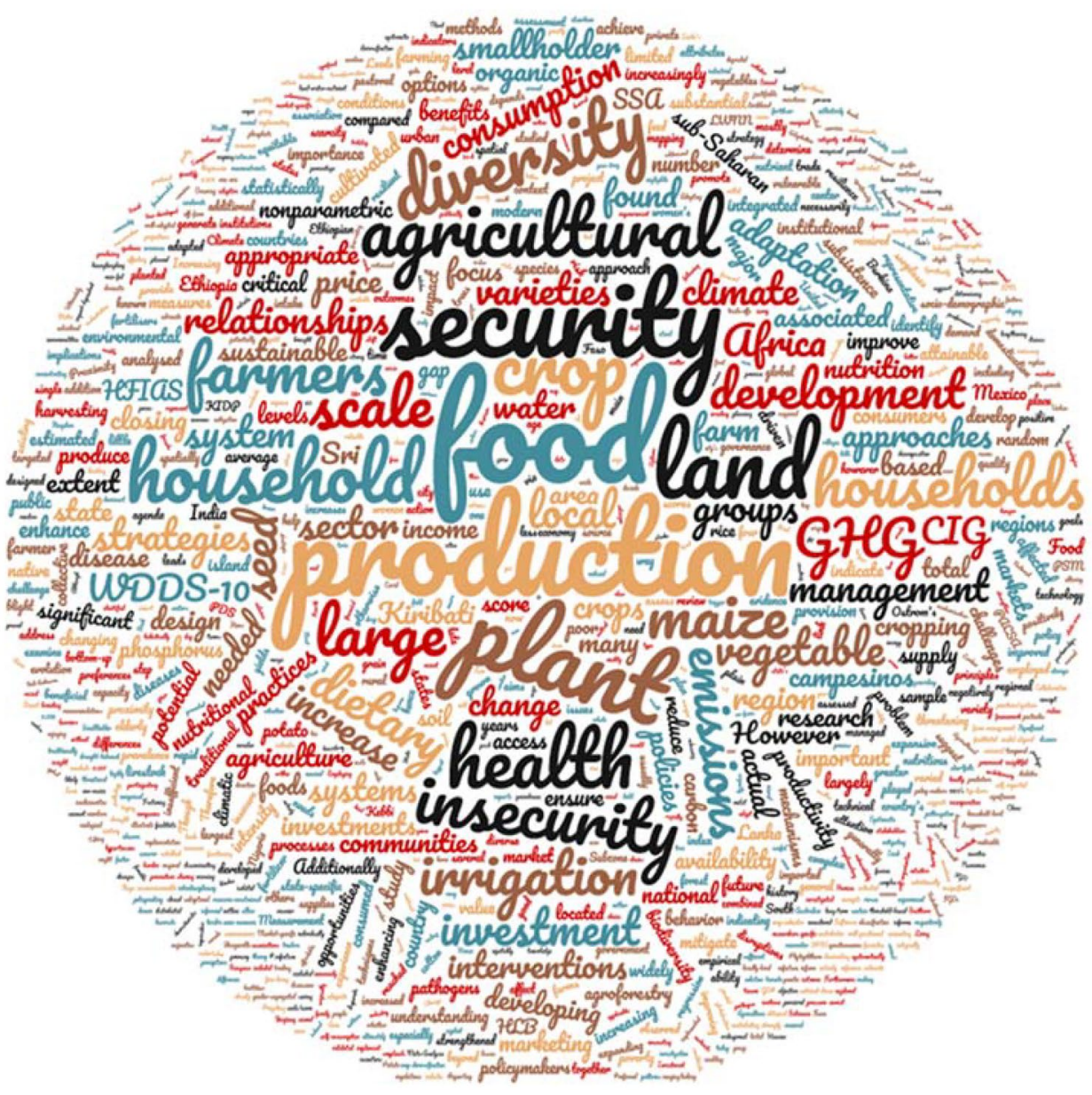

\section{The global context of 2021: food supply and demand, food prices, and global trade}

Policies that centre on trade and agricultural production remain of key interest to the audience of Food Security. van Berkum (2021) outlines priorities for food deficit low-income countries if they are to benefit from trade. This, however, may only happen if trade leads to inclusive and sustainable growth of nutritious food production. Han et al. (2021) focus on China's biofuel policy. The authors estimate a partial equilibrium model to model the possible impacts of biofuel policy on maize markets and food security. They conclude that (assuming stable macroeconomic conditions). Promotion of bioethanol in China would result in a net increase in maize imports to 26 million tons in 2030, while China's maize self-sufficiency ratio would decrease to $92 \%$. Modelling further suggests that policies promoting bioethanol in China would result in a 5\% increase of the world maize. Teklewold (2021) and Bekele et al. (2021) zoom on Ethiopia. The former article addresses the agricultural growth program and its effects on total factor productivity, while the latter investigates how proximity to large-scale land investments is linked to households' food intake and coping strategies. Teklewold (2021), unsurprisingly, concludes that there are opportunities to improve productivity growth and food security in smallholder farms through more active research and extension activities. On the other hand, Bekele et al. (2021) conclude that proximity to large scale land investments is associated with increased food intake, but has no significant effect on coping strategies to address food security.

Another recurrent theme addresses the complexity of interlinkages between poverty and food insecurity. Waarts et al. (2021) apply the living income concept to smallholder cocoa and tea farmers in Ghana, Ivory Coast and Kenya, and present an assessment approach to identify which interventions can be effective in improving farmers' livelihoods. Loibl et al. (2021) show how financial stressors are increase food insecurity among adults aged 65 years and more in the United Kingdom, Germany, and the Netherlands. This study points to the need to integrate financial and foodrelated support services in overall policies. 


\section{Food security in households in 2021}

Monitoring of food security is critical in tracking progress towards sustainable development goal (SDG) 2 of achieving zero hunger. Three articles published by Food Security in 2021 address this topic. Guha and Chandra (2021) derive reliable and representative estimates of food insecurity indicators at district level for the state of Uttar Pradesh in India, using a multivariate small area estimation technique. The approach used by Sassi and Trital (2021) highlights the temporal and spatial dynamics of food security, and relied on a multi-group piecewise latent growth curve to model food security at household level in Kenya. Odhiambo et al. (2021) compare an objective and subjective weighting approach for including the component of natural resources and resilience in the Global Food Security Index.

\section{Food production in 2021: some major trends in the year}

The production of food, vital to food security, remains an important theme. Of the 90 full articles published in 2021, almost one third (29) are mainly related to food production. More than half of these studies attempt to demonstrate linkages between food supply and other dimensions of food security such as food access to and utilization.

Linking food production to the different food security dimensions remains a challenge. Producing food sometimes seems to be a long way from to achieving food security. This relationship seems tighter in the developing world. Cause and effect relationships across the many steps between food production and food security can be difficult to demonstrate rigorously. Many articles follow the best research practices on this topic. They also illustrate some of the challenges, however. Integrated studies are very rare, where nested aggregation levels (farm household, village, watershed, region) are considered to analyse the relations between production resources (biophysical and socio-economic), agricultural technologies, food production, household income, and environmental impacts.

In the wake of the important articles by Powell et al. in 2015 and by Sibhatu and Qaim in 2018, the links between diversified agricultural production to diversity of food available and consumed, improved diets, nutrition and health, collectively have become a major theme for Food Security. At least seven articles on such topics were published in 2021. For example Sariyev et al. (2021) show that agricultural production diversity in Ethiopia can lead to better diets for poorer subsistence-farming households with little income and distant from markets. Some of these relationships can be complex as reported by Bakhtsiyarava and Grace (2021) in Ethiopia too: while increased farm production diversity (more cereals and animal products) is usually associated with reduced risk of chronic food insecurity in children, excessively diverse food production may increase food insecurity in periods of low rainfall. The contribution to food diversity from non-agricultural production is illustrated by aquaculture in Bolivia (Irwin et al., 2021) and by home gardens in Mexico (CastañedaNavarrete, 2021).

Several noteworthy articles linking agricultural resources and practices with food security were published in 2021 . Irrigation is one of the best ways to ensure high agricultural productivity, but does this translate into food security for local communities? Kassie and Alemu (2021) find that the participants of an irrigation scheme in Ethiopia achieve higher incomes, but with no effect on food security under the considered settings. Beyond merely demonstrating linkages, understanding the mechanisms by which agriculture affects food security is necessary. Madsen et al. (2021) examine how agroecologically-based soil management and crop diversification interventions affected household diets in Malawi. The study reports pathways to greater food security, which are reinforced by participatory learning, greater control over agricultural inputs and enhanced social support.

Another theme that continued to attract attention in 2021 involves change in the use and adoption of new and improved agricultural technologies and inputs, and the ensuing benefits for people and planet. This year the journal featured articles on climate-smart agricultural practices in Pakistan (ul Haq et al., 2021), fertilizer use for maize in Kenya (Jena et al., 2021) and varieties of different crops in India, Rwanda and Morocco (Danso-Abbeam et al., 2021; Kumar et al., 2021; Yigezu et al., 2021). ul Haq et al. (2021) document the adoption of a range of climate-smart practices in the Pakistan Punjab, and demonstrate that farm households using more such practices had greater food diversity and dietary intake. Not discussed in-depth so far in the literature, is what, exactly, makes some practices 'climate-smart'. This question deserves more attention in the future.

In August 2020, Food Security published a Special Issue on the expectations and early effects of the Covid-19 pandemic on food systems. A follow-up article by Jaacks et al. (2021) examines how the mid-2020 lockdown affected agricultural production in India. Farmers did experience delays in crop harvests, but reported more serious issues with the marketing of produce and a reduction in the diversity of foods available. Related articles are appearing online for full publication in 2022.

The shape of farming and agricultural production in the future, with emphasis on sub-Saharan Africa, is addressed in two articles (Giller et al., 2021a, b). The articles underline 
the multiple roles of farming and the dominance of family farms in most parts of the world. Much remains to be done to raise the economic viability of agriculture, especially in smallholder systems. The links between farming and food security are often good, but highly variable, showing the limitations of relying solely on agriculture for development. Small farms are expected to thrive and expand in size in the future. These authors emphasise the value of diversified, locally adapted and environmentally friendly farming systems.

\section{Value chains and food systems}

Food systems were the focus of a 2021 Food Security Series. A first question is whether and how food systems are changing (Leeuwis et al., 2021). An obvious element to manage and reorganise food systems, when necessary, is that there is no universal solution; food system transformation has to be adapted to contexts which differ among regions (Dengerink et al., 2021). Five paradigm shifts are advocated by Ruben et al. (2021): (1) Raise Ambitions: from food security to food system resilience; (2) Harmonize Goals: combine efficient production with affordable nutrition, inclusive livelihoods and environmental sustainability; (3) Improve Connectivity: from modular exchange to midstream interlinkages; (4) Strengthen Responsiveness: from linear agri-food value chains to circular food systems; and (5) Anchoring Governance: from targeted incentives to integrated and comprehensive food system governance. One very interesting perspective is akin to what is practiced in engineering (reverse engineering) or simulation modelling (parameter estimation via reverse modelling): in this case, reverse designing of food systems (Brouwer et al., 2021), starting with what they should deliver in the first place: healthy diets for all.

\section{Evolutions food security as a concept}

The concept of food security was first used in the mid-70 s and evolved over time (Pinstrup-Andersen, 2009). While initially referring mainly to food supply, the concept soon involved the availability and access to food. Food security now makes explicit reference to the quality of food by including nutritious and dietary needs and preferences. Attention to the latter aspect is growing in articles published in Food Security. In the considered 99 articles published in Food Security in 2021, 31 had the words "food security" (20) or "food insecurity" (11) in their title. However, only two of those titles point to nutritious aspects of food security. Among these 31 articles, 9 address the role of agricultural bio-physical production factors in food security (e.g., irrigation, plant diseases, farm trees, market incentives, agroecology, greenhouse gasses) and 13 articles consider the role of social factors in food security in food-producing households (contract farming, financial situation) or nonfood-producing households (e.g., financial situation, corruption, age, covid). The contributions that explicitly included the cultural aspects of available and accessible food (Bellon et al., 2021; Turner et al., 2021) are of particular interest and importance. Another contribution reviewed global literature to identify coping behaviours that are (a) non-food (livelihood alterations) and (2) food-based (Chaudhuri et al., 2021). The approach to assess food security had a central place in six 2021 articles, involving a number of methods (non-parametric analysis, right based analysis, use of Food Insecurity Experience Scale and Global Food Security Index).

\section{Global nutrition seen through the lens of 2021 Food Security articles}

Diverse diets and good nutrition are positive outcomes of properly functioning food systems, alongside fair livelihoods and sustainable environments. Many Food Security articles in 2021 took a perspective on these key outcomes, across multiple disciplines and methods.

One set of articles in 2021 referred to climate and agrobiodiversity and explicit links to diets and nutrition. Adding to a growing literature on links between agrobiodiversity and nutrition, Lourme-Ruiz et al. (2021) considers the linkages between production diversity and dietary diversity in Burkina Faso; Bakhtsiyarava et al. (2021) assess production diversity and child anthropometric indicators in Ethiopia; and Vogliano et al. (2021) assess links between agrobiodiversity and a set of nutrition indicators in the Solomon Islands. Explicitly addressing climate, Block et al. (2021) analyse the effects of heat shocks on child height via maize yields; while ul Haq et al. (2021) explore the adoption of climate-smart agriculture practices and assess potential effects on impacts on diets.

Another theme among the nutrition-oriented articles of 2021 is the issues of equity and empowerment. Harris et al. (2021) for instance consider how and why nutrition outcomes are poorer for ethnic minority groups in Vietnam; Lentz et al. (2021) show that women's empowerment are associated with their nutritional status in Niger; and Maia and Santos (2021) assess the socio-demographic drivers of food insecurity for children in Portugal. Focusing on interventions and actions, Cauchi et al. (2021) draw on community perspectives to understand perceptions of healthy food; and Nordhagen and Traoré (2021) examine the sustainability of women's groups in facilitating nutrition-sensitive agriculture. 
2021 also saw the beginning of a Food Security Series where 'Stories of Change in Nutrition' are told and analysed. In the introductory article, Gillespie et al. (2021) lay out the rationale for combining clear qualitative and quantitative evidence with compelling narratives to catalyse action on multiple forms of malnutrition in Africa and Asia. Two articles have been published in this series so far: Harris et al. (2021) look at the history and policy drivers of malnutrition among different ethnic groups in Vietnam; and Aryeetey et al. (2021) analyse the policy and programmatic drivers of reductions in child stunting and anaemia in Ghana. This series will continue into 2022 with several more articles.

\section{Perspectives for 2022}

Figure 1 shows how diverse the topics have been in Food Security in 2021. The analysis of the year suggests at least four lines of thoughts.

First is the question of how Food Security truly is plurior inter-disciplinary. This is a difficult question, but Fig. 1 and the present review suggest that much progress would be desirable. As vital as it may be, food production is meaningless in absence of access, and is inadequate if it does not meet the nutritional requirements of populations that are, everywhere on Earth, diverse in their own ways in age, gender, culture, and health status. More will be done in order to encourage submissions that truly are involving differing disciplinary paradigms.

Differences in disciplinary paradigms make it very hard for many truly inter-disciplinary projects to actually be funded, for scientists to work together, for students to meet academic requirements and receive their $\mathrm{PhDs}$, and for scientists to be recognised in their own institutions and disciplines. Pluridisciplinarity, which is so strongly advocated in some circles, may make scientists outliers: this is a serious issue that Science leaders must ponder and address through institutional and international policies.

One escape route towards pluridisciplinarity lies in the word: "application". Pluridisciplinary research is usually expected find its reward in practical application - however, application is something that the academia often frowns at. Yet, one should be convinced that pluridisciplinary research may (1) have the highest standards of (discipline-based) science, (2) overcome paradigm divides, (3) and lead to significant results, both in terms of academic accomplishments and in terms of practical application. One angle to see this is the importance of the collective (Nordman, 2021) in the research fields that underpin food security questions. Never have the questions connected to food security required so much science, in the physical (say: Climate Science), in the biological (say: Genetics), and in the social (say: Economy, Sociology) worlds. And never have these questions been addressing so directly what must be considered as collective goods: global climate, soil fertility, water, public health, genetic resources; and also: differing cultures, traditions, arts, and beauty; and many more.

A second line of thoughts, which derives from the first, is whether Food Security makes justice to the Social Sciences. A series of excellent articles have been published in Economy in 2021 in Food Security. But not enough is published in the fields of sociology and psychology. An illustration of this is Integrated Pest Management (IPM). IPM is a field of investigation meant to limit losses to plant pathogens and pests; it therefore involves strong involvement of the plant health sciences, of genetics and breeding, of plant physiology and microbiology, and many facets of the functioning of agrosystems. Yet never would an IPM project ever succeed without some involvement of psychology and sociology. Farming is difficult and risky; it has strong roots in traditions, perceptions and beliefs, even in the Global North; and therefore, change is hard. Further, plant health is a collective
Fig. 2 Geographical distribution of studies reported in Food Security in 2021

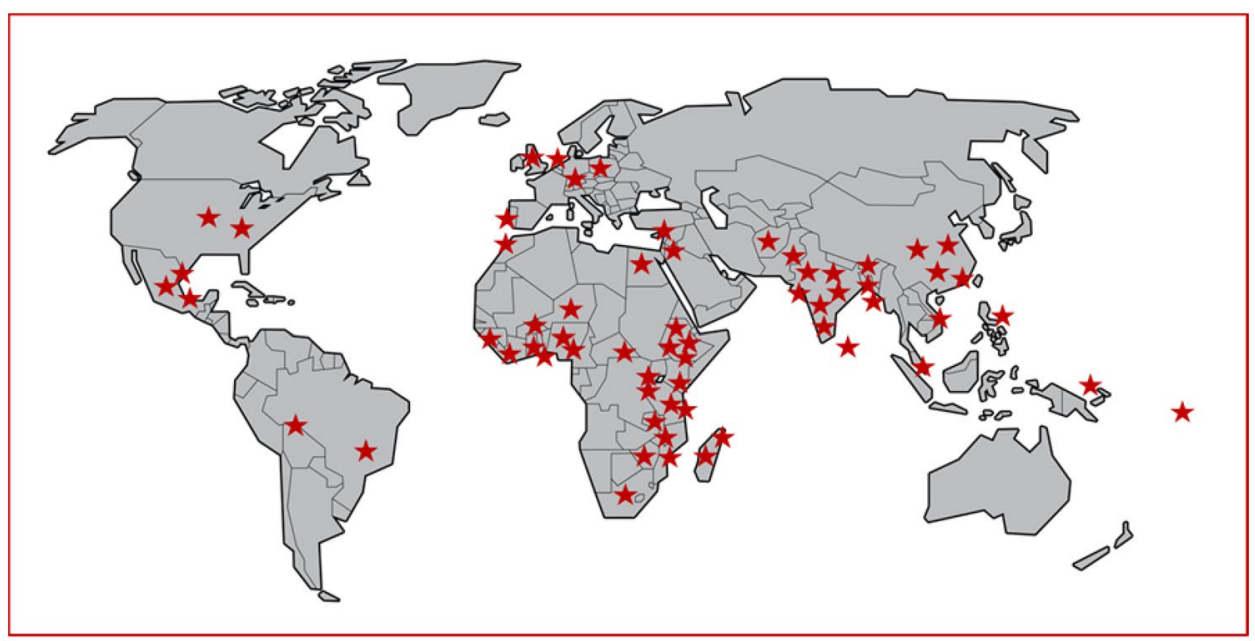


good, and therefore calls for collective actions. Collective actions have proven to be extremely effective in plant disease management (Bergamin Filho et al., 2016). Sociology and psychology are integral part of a successful research and applications in IPM. Excellent science can be published on IPM and its impacts to food security, natural resources, public health, and the environment.

A third line of thoughts is the geographical reach of Food Security. How this stands for 2021 is illustrated in Fig. 2. Obviously, the bulk of Food Security articles are rooted in the Global South. There are several reasons for this. Some are true. For instance, funding for food security-related projects nowadays is strongly oriented to the Global South. In fact, many, if not all the large funding agencies worldwide have their own "priority maps" with various countries of the Global South. Others are downright wrong. It is for instance untrue to think that food security concerns only, or mostly, the Global South. While food security is critical to the Global South, it is becoming a massive concern in several countries of the Global North today. This is also what Fig. 2 shows; the Editorial Board of Food Security will be monitoring this and ensuring balance in 2022 .

The fourth line of thoughts is that, very surprisingly, words such as "Covid" or "pandemic" are not apparent in Fig. 1. Covid, for instance, has a word count of 11 only among the 99 abstracts considered; this is too low to be clearly seen. Abstracts do not always reflect contents, however: the truth is that a very large number of Food Security articles in 2021 have had a link with the pandemic, or are influenced by it. This might even be stronger in 2022: research takes time, and so do careful review and publication. Yet, and despite the magnitude of the pandemic disaster, there is this sinking feeling that so many (only slightly) longer-term issues are being overlooked: the global population growth, climate change, the collapse of biological diversity, the shortage of resources, or the disappearance of cultures and know-how. All these issues, and others, will be considered in 2022, because they all impact food security.

\section{References}

Aryeetey, R., Atuobi-Yeboah, A., Billings, L., Nisbett, N., van den Bold, M., \& Toure, M. (2021). Stories of change in nutrition in Ghana: A focus on stunting and anemia among children underfive years (2009-2018). Food Security. https://doi.org/10.1007/ s12571-021-01232-1

Bakhtsiyarava, M., \& Grace, K. (2021). Agricultural production diversity and child nutrition in Ethiopia. Food Security, 13(6), 14071422. https://doi.org/10.1007/s12571-021-01173-9

Bakhtsiyarava, M., Williams, T. G., Verdin, A., \& Guikema, S. D. (2021). A nonparametric analysis of household-level food insecurity and its determinant factors: Exploratory study in Ethiopia and Nigeria. Food Security, 13(1), 55-70.
Bekele, A. E., Dries, L., Heijman, W., \& Drabik, D. (2021). Large scale land investments and food security in agropastoral areas of Ethiopia. Food Security, 13(2), 309-327.

Bergamin Filho, A., Inoue-Nagata, A. K., Bassanezi, R. B., Belasque, J., Amorim, L., Macedo, M. A., Barbosa, J. C., Willocquet, L., \& Savary, S. (2016). The importance of primary inoculum and area-wide disease management to crop health and food security. Food Security, 8, 221-238.

van Berkum, S. (2021). How trade can drive inclusive and sustainable food system outcomes in food deficit low-income countries. Food Security, 13(6), 1541-1554.

Bellon, M. R., Mastretta-Yanes, A., Ponce-Mendoza, A., Ortiz-Santa Maria, D., Oliveros-Galindo, O., Perales, H., Acevedo, F., \& Sarukhan, J. (2021). Beyond subsistence: The aggregate contribution of campesinos to the supply and conservation of native maize across Mexico. Food Security, 13, 39-53.

Block, S., Haile, B., You, L., \& Headey, D. (2021). Heat shocks, maize yields, and child height in Tanzania. Food Security. https://doi. org/10.1007/s12571-021-01211-6

Brouwer, I. D., van Liere, M. J., \& Ruel, M. (2021). Reverse thinking: Taking a healthy diet perspective towards food systems transformations. Food Security, 13, 1497-1523.

Castañeda-Navarrete, J. (2021). Homegarden diversity and food security in southern Mexico. Food Security, 13(3), 669-683. https:// doi.org/10.1007/s12571-021-01148-w

Cauchi, J. P., Bambrick, H., Moncada, S., \& Correa-Velez, I. (2021). Nutritional diversity and community perceptions of health and importance of foods in Kiribati: A case study. Food Security, 13(2), 351-367.

Chaudhuri, S., Roy, M., McDonald, L. M., \& Emendack, Y. (2021). Coping Behaviours and the concept of Time Poverty: A review of perceived social and health outcomes of food insecurity on women and children. Food Security, 13, 1049-1068.

Danso-Abbeam, G., Baiyegunhi, L. J. S., Laing, M. D., et al. (2021). Food security impacts of smallholder farmers' adoption of dualpurpose sweetpotato varieties in Rwanda. Food Security, 13(3), 653-668. https://doi.org/10.1007/s12571-020-01119-7

Dengerink, J., Dirks, F., Likoko, E., \& Guijt, J. (2021). One size doesn't fit all: Regional differences in priorities for food system transformation. Food Security, 13, 1455-1466.

Giller, K. E., Delaune, T., Silva, J. V., et al. (2021a). The future of farming: Who will produce our food? Food Security, 13(5), 10731099. https://doi.org/10.1007/s12571-021-01184-6

Giller, K. E., Delaune, T., Silva, J. V., et al. (2021b). Small farms and development in sub-Saharan Africa: Farming for food, for income or for lack of better options? Food Security, 13(6), 1431-1454. https://doi.org/10.1007/s12571-021-01209-0

Gillespie, S., Harris, J., Nisbett, N., \& van den Bold, M. (2021). Stories of change in nutrition from Africa and Asia: An introduction to a special series in Food Security. Food Security, 13, 799-802.

Guha, S., \& Chandra, H. (2021). Measuring disaggregate level food insecurity via multivariate small area modelling: Evidence from rural districts of Uttar Pradesh. Food Security. https://doi.org/10. 1007/s12571-021-01143-1

Han, X., Chen, Y., \& Wang, X. (2021). Impacts of China's bioethanol policy on the global maize market: A partial equilibrium analysis to 2030. Food Security. https://doi.org/10.1007/ s12571-021-01212-5

ul Haq, S., Boz, I., \& Shahbaz, P. (2021). Adoption of climate-smart agriculture practices and differentiated nutritional outcome among rural households: A case of Punjab province, Pakistan. Food Security, 13, 913-931. https://doi.org/10.1007/s12571-021-01161-z

Harris, J., Huynh, P., Nguyen, H. T., Hoang, N., Mai, L. T., Tuyen, L. D., \& Nguyen, P. H. (2021). Nobody left behind? Equity and the drivers of stunting reduction in Vietnamese ethnic minority populations. Food Security, 13(4), 803-818. 
Irwin, S., Flaherty, M. S., \& Carolsfeld, J. (2021). The contribution of small-scale, privately owned tropical aquaculture to food security and dietary diversity in Bolivia. Food Security, 13(1), 199-218. https://doi.org/10.1007/s12571-020-01104-0

Jaacks, L. M., Veluguri, D., Serupally, R., et al. (2021). Impact of the COVID-19 pandemic on agricultural production, livelihoods, and food security in India: Baseline results of a phone survey. Food Security, 13(5), 1323-1339. https://doi.org/10.1007/ s12571-021-01164-w

Jena, P. R., De Groote, H., Nayak, B. P., et al. (2021). Evolution of fertiliser use and its Impact on maize productivity in Kenya: Evidence from multiple surveys. Food Security, 13(1), 95-111. https://doi. org/10.1007/s12571-020-01105-Z

Kassie, K. E., \& Alemu, B. A. (2021). Does irrigation improve household's food security? The case of Koga irrigation development project in northern Ethiopia. Food Security, 13(2), 291-307. https://doi.org/10.1007/s12571-020-01129-5

Kumar, A., Hazrana, J., Negi, D. S., et al. (2021). Understanding the geographic pattern of diffusion of modern crop varieties in India: A multilevel modeling approach. Food Security, 13(3), 637-651. https://doi.org/10.1007/s12571-020-01114-y

Leeuwis, C., Boogaard, B. K., \& Atta-Krah, K. (2021). How food systems change (or not): Governance implications for system transformation processes. Food Security, 13, 761-780.

Lentz, E., Bageant, E., \& Narayanan, S. (2021). Empowerment and nutrition in Niger: Insights from the women's empowerment in nutrition grid. Food Security, 13, 1227-1244.

Loibl, C., Bruine de Bruin, W., Summers, B., McNair, S., \& Verhallen, P. (2021) Which financial stressors are linked to food insecurity among older adults in the United Kingdom, Germany, and the Netherlands? An exploratory study. Food Security. https://doi.org/ 10.1007/s12571-021-01206-3

Lourme-Ruiz, A., Dury, S., \& Martin-Prével, Y. (2021). Linkages between dietary diversity and indicators of agricultural biodiversity in Burkina Faso. Food Security, 13(2), 329-349.

Madsen, S., Bezner Kerr, R., LaDue, N., et al. (2021). Explaining the impact of agroecology on farm-level transitions to food security in Malawi. Food Security, 13(4), 933-954. https://doi.org/10.1007/ s12571-021-01165-9

Maia, I., \& Santos, A. C. (2021). Prevalence and determinants of children self-reports of food insecurity: Evidence from a Portuguese population-based birth cohort. Food Security. https://doi.org/10. 1007/s12571-021-01233-0

Nordhagen, S., \& Traoré, A. (2021). Group-based approaches to nutrition-sensitive agriculture: Insights from a post-project sustainability study in Côte d'Ivoire. Food Security. https://doi.org/ 10.1007/s12571-021-01229-w

Nordman, E. (2021) The uncommon knowledge of Elinor Ostrom: Essential lessons for collective action. Island Press.
Odhiambo, V. O., Hendriks, S. L., \& Mutsvangwa-Sammie, E. P. (2021). The effect of an objective weighting of the global food security index's natural resources and resilience component on country scores and ranking. Food Security. https://doi.org/10. 1007/s12571-021-01176-6

Pinstrup-Andersen, P. (2009). Food security: Definition and measurement. Food Security, 1(1), 5-7.

Powell, B., Thilsted, S. H., Ickowitz, A., et al. (2015). Improving diets with wild and cultivated biodiversity from across the landscape. Food Security, 7(3), 535-554. https://doi.org/10.1007/ s12571-015-0466-5

Ruben, R., Cavatassi, R., \& Winters, P. (2021). Towards food systems transformation-five paradigm shifts for healthy, inclusive and sustainable food systems. Food Security, 13, 1423-1430.

Sariyev, O., Loos, T. K., \& Khor, L. Y. (2021). Intra-household decision-making, production diversity, and dietary quality: A panel data analysis of Ethiopian rural households. Food Security, 13(1), 181-197. https://doi.org/10.1007/s12571-020-01098-9

Sassi, M., \& Trital, G. (2021) A latent growth curve modelling approach to seasonal and spatial dynamics of food security heterogeneities in rural Lake Naivasha Basin, Kenya. Food Security. https://doi.org/10.1007/s12571-021-01200-9

Sibhatu, K. T., \& Qaim, M. (2018). Farm production diversity and dietary quality: Linkages and measurement issues. Food Security, 10(1), 47-59. https://doi.org/10.1007/s12571-017-0762-3

Teklewold, H. (2021). How effective is Ethiopia's agricultural growth program at improving the total factor productivity of smallholder farmers? Food Security. https://doi.org/10.1007/ s12571-021-01175-7

Turner, M. D., Teague, M., \& Ayantunde, A. (2021). Livelihood, culture and patterns of food consumption in rural Burkina Faso. Food Security, 13, 1193-1213.

Vogliano, C., Raneri, J. E., Coad, J., Tutua, S., Wham, C., Lachat, C., \& Burlingame, B. (2021). Dietary agrobiodiversity for improved nutrition and health outcomes within a transitioning indigenous Solomon Island food system. Food Security, 13, 819-847.

Waarts, Y. R., Janssen, V., Aryeetey, R., Onduru, D., Heriyanto, D., Aprillya, S., N'Guessan, A., Courbois, L., Bakker, D., \& Ingram, V. J. (2021). Multiple pathways towards achieving a living income for different types of smallholder tree-crop commodity farmers. Food Security, 13(6), 1467-1496.

Yigezu, Y. A., Bishaw, Z., Niane, A. A., et al. (2021). Institutional and farm-level challenges limiting the diffusion of new varieties from public and CGIAR centers: The case of wheat in Morocco. Food Security, 13(6), 1359-1377. https://doi.org/10.1007/ s12571-021-01191-7 